Article

\title{
Synthesis and Bioactivity Characterization of Scutellarein Sulfonated Derivative
}

\author{
Ting Gu ${ }^{1,2}$, Yue Zhong ${ }^{1,2}$, Yu-Ting Lu ${ }^{1,2}$, Ying Sun ${ }^{1,2}$, Ze-Xi Dong ${ }^{1,2}$, Wen-Yu Wu ${ }^{1,2}$, \\ Zhi-Hao Shi ${ }^{3}$, Nian-Guang Li 1,2,*, Xin Xue ${ }^{1,2}$, Fang Fang 1,2, He-Min Li 1,2 and Yu-Ping Tang 1,* \\ 1 National and Local Collaborative Engineering Center of Chinese Medicinal Resources Industrialization and \\ Formulae Innovative Medicine, Nanjing University of Chinese Medicine, Nanjing 210023, Jiangsu, China; \\ guting1992@163.com (T.G.); 18260028701@163.com (Y.Z.); lyt1996tian@outlook.com (Y.-T.L.); \\ 18260028601@163.com (Y.S.); dongzexi1215@163.com (Z.-X.D.); 15150513147@163.com (W.-Y.W.); \\ xuexin0540121@163.com (X.X.); fylffh@163.com (F.F.); lihemin2006@sina.com (H.-M.L.) \\ 2 Department of Medicinal Chemistry, Nanjing University of Chinese Medicine, Nanjing 210023, \\ Jiangsu, China \\ 3 Department of Organic Chemistry, China Pharmaceutical University, Nanjing 211198, Jiangsu, China; \\ sszh163@163.com \\ * Correspondence: linianguang@njutcm.edu.cn (N.-G.L.); yupingtang@njutcm.edu.cn (Y.-P.T.); \\ Tel./Fax: +86-25-8581-1916 (N.-G.L.); +86-25-8581-1916 (Y.-P.T.)
}

Received: 27 May 2017; Accepted: 20 June 2017; Published: 21 June 2017

\begin{abstract}
Scutellarin (1) has been widely used to treat acute cerebral infarction in clinic, but poor aqueous solubility decreases its bioavailability. Interestingly, scutellarin (1) could be metabolized into scutellarein (2) in vivo. In this study, a sulfonic group was introduced at position C-8 of scutellarein (2) to enhance the aqueous solubility of the obtained derivative (3). DPPH (1,1-diphenyl-2-picrylhydrazyl)-radical scavenging ability and antithrombic activity were also conducted to determine its bioactivity. The result showed that scutellarein derivate (3) could be a better agent for ischemic cerebrovascular disease treatment.
\end{abstract}

Keywords: scutellarin; scutellarein; sulfonated derivative; solubility; antioxidant; antithrombic

\section{Introduction}

Ischemic cerebrovascular disease is a common and high-incidence disease that threatens human health seriously by severe neuronal injury and loss of brain function [1]. Stroke is a typical symptom of ischemic cerebrovascular disease, and causes $9 \%$ of all deaths worldwide [2]. Thus, serious harm of individual's physical, mental, and social functioning can occur as a result of ischemic cerebrovascular diseases $[3,4]$.

Erigeron breviscapus (Vant.) Hand-Mazz is one of the well-known Chinese herbs, and has an extensive application in traditional Chinese medicine treatment. The mechanism of E. breviscapus has aroused increasing attention because of its significant curative effect. Liu studied the antioxidant activity of the ethanol extract of E. breviscapus, and revealed it played an important role in neuroprotective actions [5]. Tao also found that E. breviscapus ethanol extract had therapeutic applications in neurological diseases due to the inhibition of $\gamma$-aminobutyric acid transaminase (GABA-T) and succinic semialdehyde dehydrogenase (SSADH) [6].

By modern analysis methods, scutellarin (4',5,6-trihydroxyflavone-7-glucuronide) (1) (Figure 1) could be confirmed as an important active ingredient in Erigeron breviscapus (Vant.) Hand-Mazz $[7,8]$. Ke found that scutellarin could inhibit hepatocellular carcinoma (HCC) cell metastasis in vivo, and migration and invasion in vitro by downregulating the STAT3/Girdin/Akt signaling [9]. Further, in Li's research, scutellarin could attenuate vasospasm and neurological deficits by modulating the 
Erk5-KLF2-eNOS pathway after subarachnoid hemorrhage (SAH) [10]. Furthermore, Zhao found that scutellarin was a promising therapeutic agent for the prevention of wear particle-induced periprosthetic osteolysis [11]. In addition, scutellarin (1) is effective in treating cerebral ischemia, angina pectoris, myocardial infarction, stroke, cerebral thrombotic diseases and other kinds of cardiovascular diseases and cerebrovascular injury [12].

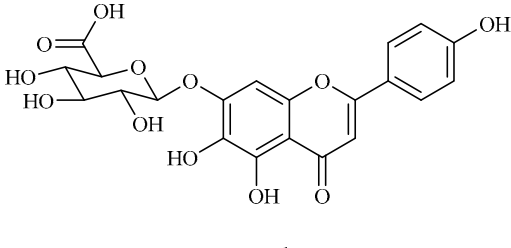

1

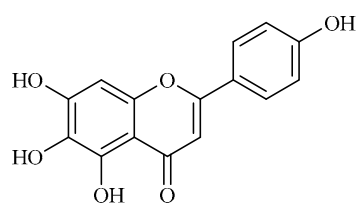

2

Figure 1. Structures of scutellarin (1) and scutellarein (2).

However, because of the poor aqueous solubility $(14.4 \pm 0.17 \mu \mathrm{g} / \mathrm{mL})$ [13], and the absolute oral low bioavailability in Beagle dog (0.4\%) [14], there is not a wide range of applications of scutellarin (1) in clinic. Structure modification and dosage form transformation are two common methods used to increase the bioavailability of this kind of natural product. By the approaches of being bound to polyrotaxane (PR) [15], adopting different lipid excipients such as cremophor EL [16], or synthesizing glucose-containing scutellarein derivatives [17], the bioavailability of scutellarin (1) can be improved to some extent.

Scutellarein (2) (Figure 1) is the hydrolysate of scutellarin (1), and is the main absorbing form in vivo [18]. Our previous work indicated that scutellarein (2) displayed better protective effect in rat cerebral ischemia than scutellarin (1) $[19,20]$. Nevertheless, the problem of poor aqueous solubility is still not resolved due to the flavonoid skeleton of scutellarein (2).

Sulfonation is an important reaction in increasing the solubility of flavonoids while retaining the chemical properties of the parent compounds [21]; as a well-known type of in vivo metabolic conversion, it also enhances the aqueous solubility of the ingested compounds [22]. Quercetin is a typical flavonoid with an antiproliferative effect on a wide range of cancer cells [23-25]. Cui, Woźnicka, and Zhang introduced sulfonic groups on quercetin $[21,22,26]$, and all of these quercetin derivatives showed good aqueous solubility on the basis of bioactivity preservation.

Therefore, in this research, we synthesized the sulfonated derivative of scutellarein (2), and a series of biological activity assays including aqueous solubility, (1,1-diphenyl-2-picrylhydrazyl) (DPPH)-radical scavenging ability, and antithrombic activity were also conducted to study its biological activity.

\section{Results and Discussion}

\subsection{Chemical Synthesis}

In this study, one of our previous methods was applied to synthesize scutellarein (2) by the hydrolysis of scutellarin (1) [19]. In this method, $3.0 \mathrm{~mol} / \mathrm{L} \mathrm{H}_{2} \mathrm{SO}_{4}$ in $90 \%$ ethanol and heating under a $\mathrm{N}_{2}$ atmosphere at $120^{\circ} \mathrm{C}$ for $48 \mathrm{~h}$ were selected as the best condition for the synthesis of scutellarein (2), and the yield could be up to $17.3 \%$. Subsequently, concentrated sulfuric acid-as reactant and solvent-was adopted to introduce a sulfonic group at the C-8 position of the scutellarein (2). The reaction temperature should be controlled at about $25{ }^{\circ} \mathrm{C}$ to avoid the side reaction in $\mathrm{B}$ ring. According to the ${ }^{1} \mathrm{HNMR}$ spectrum of 3 , the coupling constants of $\mathrm{C} 2^{\prime}, 6^{\prime}-\mathrm{H}$ and $\mathrm{C} 3^{\prime}, 5^{\prime}-\mathrm{H}$ were both 8.7, which indicated that the sulfonic group was not at $C 2^{\prime}, 6^{\prime}$ and $\mathrm{C}^{\prime}, 5^{\prime}$ positions. Furthermore, the hydrogen signal at $\delta 6.72$ of $\mathrm{C} 3-\mathrm{H}$ was still present; this information confirmed that the sulfonic group was introduced at the C-8 position. The synthesis route is shown in Scheme 1. 

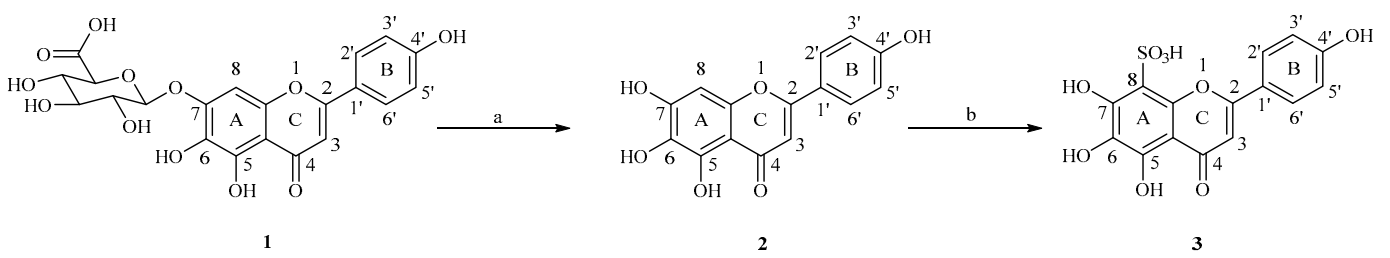

Scheme 1. The route of the synthesis of scutellarein derivate (3). (a) $\mathrm{H}_{2} \mathrm{SO}_{4}, \mathrm{EtOH}, 120{ }^{\circ} \mathrm{C}, 48 \mathrm{~h}, 17.3 \%$; (b) $\mathrm{H}_{2} \mathrm{SO}_{4}, 25^{\circ} \mathrm{C}, 3 \mathrm{~h}, 18 \%$.

\subsection{Aqueous Solubility}

The aqueous solubility of scutellarin (1), scutellarein (2), and 3 were determined by UV spectrophotometry [27-29]. As presented in Table 1, the aqueous solubility of scutellarin (1), scutellarein (2), and 3 were $7.62,6.85$, and $1949.64 \mu \mathrm{g} / \mathrm{mL}$, respectively. The results showed that the introduction of the sulfonic group increased its aqueous solubility significantly compared to scutellarin (1) and scutellarein (2).

Table 1. The solubility in water and antioxidant activity of scutellarin (1), scutellarein (2), and 3. DPPH:

(1,1-diphenyl-2-picrylhydrazyl).

\begin{tabular}{ccc}
\hline Compd. & Solubility $(\mu \mathrm{g} / \mathrm{mL})$ & DPPH $(\mu \mathrm{M})$ \\
\hline Scutellarin $(\mathbf{1})$ & 7.62 & 17.88 \\
Scutellarein $(\mathbf{2})$ & 6.85 & 16.05 \\
$(\mathbf{3})$ & 1949.64 & 16.78 \\
\hline
\end{tabular}

\subsection{DPPH-Radical Scavenging Ability Assay}

Antioxidants play important roles in removing free radicals, as antioxidants provide hydrogen to free radicals and prohibit the adverse reactions from destroying normal tissues. This assay was measured according to previous studies [30]. The results are displayed in Table 1.

As shown in the results, scutellarin (1), scutellarein (2), and $\mathbf{3}$ all exhibited good DPPH-radical scavenging ability in this assay, as the values of $\mathrm{IC}_{50}$ were $17.88,16.05$, and $16.78 \mu \mathrm{M}$, respectively, which indicated that compound 3 still had antioxidant activity.

\subsection{Antithrombic Assay}

According to our previous studies, the antithrombotic activity could be estimated by measuring the prolongation of the plasma clotting time of thrombin time (TT), activated partial thromboplastin time (APTT), international normalized ratio (INR) increase in prothrombin time (PT), and reduction in fibrinogen (FIB) content [31]. The results are displayed in Table 2.

Table 2. The thrombin inhibition activity of scutellarin (1), scutellarein (2), and 3. APTT: activated partial thromboplastin time; FIB: fibrinogen; PT: prothrombin time; TT: thrombin time.

\begin{tabular}{ccccc}
\hline \multirow{2}{*}{ Compd. } & \multicolumn{4}{c}{ Plasma Coagulation Parameters } \\
\cline { 2 - 5 } & TT (s) & APTT (s) & PT (s) & FIB (g/L) \\
\hline Blank plasma & $19.85 \pm 1.59$ & $29.83 \pm 3.86$ & $5.03 \pm 0.24$ & $7.23 \pm 0.38$ \\
Scutellarin (1) & $23.25 \pm 1.55$ & $33.78 \pm 2.32$ & $6.25 \pm 0.08$ & $6.41 \pm 0.15$ \\
Scutellarein (2) & $24.48 \pm 1.18$ & $36.12 \pm 2.20$ & $5.93 \pm 0.81$ & $6.91 \pm 0.12$ \\
3 & $23.71 \pm 1.82$ & $30.33 \pm 1.06$ & $6.33 \pm 1.87$ & $7.01 \pm 0.96$ \\
\hline
\end{tabular}

Data represent mean $\pm \mathrm{SD} n=4$. 
As the results show, the antithrombotic activity was remained when the glucuronyl group in scutellarin (1) was hydrolyzed to produce scutellarein (2); although the PT decreased and the FIB content increased in scutellarein (2), the TT and APTT in scutellarein (2) increased compared with those in scutellarin (1); this result indicated that the glucuronyl group was not important for the antithrombotic activity.

The results also indicated that scutellarein derivative with a sulfonic group at the C-8 position (3) could retain the antithrombotic activity. On the one hand, the introduction of a sulfonic group at the C-8 position increased TT and PT significantly compared with the control group. Specifically, the TT prolongation of scutellarein derivative (3) (23.71 s) was better than scutellarin (1) (23.25 s), but inferior to scutellarein (2) (24.48 s); nevertheless, the PT prolongation of scutellarein derivative (3) (6.33 s) was superior to scutellarin (1) (6.25 s) and scutellarein (2) (5.93 s). On the other hand, the introduction of a sulfonic group at the C-8 position of scutellarein (3) increased APTT and decreased FIB to some degree in comparison to the control group; however, the improvement of APTT (30.33 s) and FIB (7.01 g/L) was not as good as scutellarin (1) (APTT: 33.78 s, FIB: $6.41 \mathrm{~g} / \mathrm{L}$ ) and scutellarein (2) (APTT: $36.12 \mathrm{~s}$, FIB: $6.91 \mathrm{~g} / \mathrm{L})$.

Thus, the introduction of sulfonic group at C-8 position of the scutellarein (3) could retain the antithrombotic activity of the parent compounds.

\section{Experimental Section}

\subsection{General Information}

Scutellarin (1) was purchased from Sichuan Mianning Jiexiang Materials Co. Ltd. (Chengdu, China). Reagents and solvents were purchased from commercial sources and used without further purification unless otherwise specified. All non-aqueous reactions were carried out under nitrogen production using flame-dried glassware; the anhydrous solvents were transferred via syringe or stainless steel cannula. Organic solvents were concentrated below $45^{\circ} \mathrm{C}$ by Büchi rotary evaporator at approximately $20 \mathrm{~mm} \mathrm{Hg}$. Then, $0.15-0.20 \mathrm{~mm}$ silica gel plates (RSGF 254, Yantai, China), as thin-layer chromatography (TLC), was used to monitored all of the reactions in $254 \mathrm{~nm}$ UV light. Chromatography was carried out on silica gel (160-200 mesh, Qingdao, China) with mixtures of petroleum ether (60-90) and ethyl acetate as eluant. The ${ }^{1} \mathrm{H}$ NMR spectroscopy was carried out on a Bruker AV-300 (300 MHz) (Bruker Corporation, Karlsruhe, Germany) in DMSO- $d_{6}$. Abbreviations used are s (singlet), d (doublet), $\mathrm{t}$ (triplet), q (quartet), b (broad), and $\mathrm{m}$ (multiplet). Mass spectrometry (MS) were performed on a Waters Synapt HDMS spectrometer equipped with an electrospray ionization source (ESI).

\subsection{Synthesis}

\subsubsection{5,6,7-Trihydroxy-2-(4-hydroxyphenyl)-4H-chromen-4-one (2)}

Concentrated $\mathrm{H}_{2} \mathrm{SO}_{4}(100 \mathrm{~mL})$ was added into a stirring mixture of $\mathbf{1}(10 \mathrm{~g}, 21.65 \mathrm{mmol})$ and water $(10 \mathrm{~mL})$ in ethanol $(90 \mathrm{~mL})$, and the reaction mixture was refluxed for $48 \mathrm{~h}$ under nitrogen and then was allowed to cool to room temperature. Water $(1000 \mathrm{~mL})$ was added, and the solid that appeared was filtered and then purified by column chromatography on silica gel with $50 \%$ ethyl acetate in petroleum ether as eluent to afford 1 (1.05 g, 17\% yield) as a yellow solid. IR (KBr): 3343.24, 1663.08, 1610.20, $1580.85,1458.41,1364.24,1270.26,1252.35,1183.51,1079.25,1028.97,1004.24,830.86,721.26,598.71$, $574.65 \mathrm{~cm}^{-1}$. ${ }^{1} \mathrm{H}-\mathrm{NMR}\left(\mathrm{DMSO}-d_{6}\right) 6.73(\mathrm{~s}, 1 \mathrm{H}, 8-\mathrm{H}), \delta 6.78(\mathrm{~s}, 1 \mathrm{H}, 3-\mathrm{H}), 6.90-6.93(\mathrm{~d}, 2 \mathrm{H}, \mathrm{J}=8.8 \mathrm{~Hz}$, $\left.3^{\prime}, 5^{\prime}-\mathrm{H}\right), 7.90-7.93\left(\mathrm{~d}, 2 \mathrm{H}, J=8.8 \mathrm{~Hz}, 2^{\prime}, 6^{\prime}-\mathrm{H}\right), 8.71(\mathrm{~s}, 1 \mathrm{H}, 6-\mathrm{OH}), 10.30\left(\mathrm{~s}, 1 \mathrm{H}, 4^{\prime}-\mathrm{OH}\right), 10.44(\mathrm{~s}, 1 \mathrm{H}, 7-\mathrm{OH})$, 12.79 (s, 1H, 5-OH); ESI-MS: $m / z 285[\mathrm{M}-\mathrm{H}]^{-}$; Anal. Calcd. for $\mathrm{C}_{15} \mathrm{H}_{10} \mathrm{O}_{6}$ : C, 62.94; H, 3.52; Found: $\mathrm{C}, 62.92 ; \mathrm{H}, 3.49$. The IR and ${ }^{1} \mathrm{H}-\mathrm{NMR}$ spectrums were included in the Supplementary Materials available online. 


\subsubsection{5,6,7-Trihydroxy-2-(4-hydroxyphenyl)-4-oxo-4H-chromene-8-sulfonic acid (3)}

Concentrated sulfuric acid $(15 \mathrm{~mL})$ was added to $2(1.0 \mathrm{~g})$ in a $50 \mathrm{~mL}$ round-bottom flask, the reaction mixture was allowed to continue stirring for $12 \mathrm{~h}$ at $25^{\circ} \mathrm{C}$. After that, $25 \mathrm{~mL}$ of saturated sodium chloride solution was added into the mixture, and the mixture was kept for $4 \mathrm{~h}$ before filtering. The orange-red precipitate was washed with saturated sodium chloride solution until the $\mathrm{pH}$ value of the filtrate was up to 7, and was then recrystallized twice from the hot saturated aqueous solution; 3 (230 mg, 18\% yield) was obtained as yellow solid. IR (KBr): 3272.90, 2918.66, 1659.91, 1592.18, 1558.24, 1472.13, 1417.77, 1373.40, 1321.34, 1259.45, 1229.59, 1163.55, 1105.26, 1025.93, 672.43, 579.93, $522.46 \mathrm{~cm}^{-1} .{ }^{1} \mathrm{H}-\mathrm{NMR}$ (DMSO-d $\left.d_{6}\right) \delta 6.72(1 \mathrm{H}, \mathrm{s}, 3-\mathrm{H}), 6.97-6.99\left(2 \mathrm{H}, \mathrm{d}, J=8.7 \mathrm{~Hz}, 3^{\prime}, 5^{\prime}-\mathrm{H}\right), 8.27-8.30$ $\left(2 \mathrm{H}, \mathrm{d}, J=8.7 \mathrm{~Hz}, 2^{\prime}, 6^{\prime}-\mathrm{H}\right), 8.55(1 \mathrm{H}, \mathrm{s}, 6-\mathrm{OH}), 11.13(1 \mathrm{H}, \mathrm{s}, 4-\mathrm{OH}), 12.52(1 \mathrm{H}, \mathrm{s}, 7-\mathrm{OH}), 12.99(1 \mathrm{H}$, s, 5-OH); ESI-MS: $m / z 365[\mathrm{M}-\mathrm{H}]^{-}$; Anal. Calcd. for $\mathrm{C}_{15} \mathrm{H}_{10} \mathrm{O}_{9} \mathrm{~S}: \mathrm{C}, 49.19 ; \mathrm{H}, 2.75$; S, 8.75; Found: $\mathrm{C}, 49.21 ; \mathrm{H}, 2.78 ; \mathrm{S}$. 8.77. The IR and ${ }^{1} \mathrm{H}-\mathrm{NMR}$ spectrums were included in the Supplementary Materials available online.

\subsection{Aqueous Solubility}

The solubility of scutellarin (1), scutellarein (2), and $\mathbf{3}$ in water was determined using the known method [27-29]. According to multicomponent exploitation method, $334 \mathrm{~nm}$ could be considered as the wavelength of maximum absorbance of scutellarein (2) by UV absorption spectrophotometry. Scutellarin (1) and scutellarein (2) $(300 \mu \mathrm{g})$ were dissolved in $25 \mathrm{~mL} \mathrm{CH}_{3} \mathrm{OH}$, and 3 (300 $\left.\mu \mathrm{g}\right)$ was dissolved in $25 \mathrm{~mL}$ water. The solutions of these three compounds had concentrations ranging from 3 to $12 \mu \mathrm{g} / \mathrm{mL}$. Standard curves were determined on the basis of the absorbances of test samples obtained by UV scanning, and all of them showed a good linear relationship. Each tested compound $\left(250 \mu \mathrm{g}\right.$ ) was ultrasound dissolved in $10 \mathrm{~mL}$ pure water for $1 \mathrm{~h}$ at $25^{\circ} \mathrm{C}$, and the solutions were stood for $30 \mathrm{~min}$ before centrifuging at the speed of 30,000 r/min. Absorbances of each compound were obtained by UV scanning, and the aqueous solubility of all three compounds were obtained through analysis of the standard curve.

\subsection{DPPH-Radical Scavenging Ability Assay}

The following method was adopted to evaluate the 1,1-diphenyl-2-picrylhydrazyl (DPPH) scavenging property of the products: scutellarin (1), scutellarein (2), and 3 were dissolved in DMSO to result in final concentrations ranging from 16 to $250 \mu \mathrm{mol} / \mathrm{L}$, and then DPPH $(80 \mu \mathrm{mol} / \mathrm{L}, 100 \mu \mathrm{L})$ dissolved in DMSO was added in the testing samples. After incubating for $30 \mathrm{~min}$ in the dark, the scavenging effect was calculated according to the following equation:

$$
\text { Scavenging effect }(\%)=\left[\left(1-\left(\mathrm{A}_{1}-\mathrm{A}_{2}\right) / \mathrm{A}_{0}\right] \times 100 \%\right.
$$

where $A_{0}$ is the absorbance of the control (without extract), $A_{1}$ is the absorbance in the presence of the extract, and $\mathrm{A}_{2}$ is the absorbance without DPPH.

\subsection{Antithrombic Assay}

Male New Zealand white rabbits weighing 2-2.5 $\mathrm{kg}$ were obtained from the experimental animal center of Nanjing University of Chinese Medicine and were approved by Animal Ethics Committee of Nanjing University of Chinese Medicine. They were kept in plastic cages at $22 \pm 2{ }^{\circ} \mathrm{C}$ with free access to pellet food and water and on a $12 \mathrm{~h}$ light/dark cycle. Animal welfare and experimental procedures were carried out in accordance with the guide for the care and use of laboratory animals (National Research Council of USA, 1996) and related ethical regulations of Nanjing University of Chinese Medicine. Rabbits were anesthetized with pentobarbital $(50 \mathrm{mg} / \mathrm{kg}$ ) and blood was drawn from the common carotid artery. Blood was collected into plastic tubes with $3.8 \%$ sodium citrate (citrate/blood: 1:9, v/v) for plasma anticoagulation. Platelet-poor plasma (PPP) was separated from blood by centrifugation at $3000 \mathrm{rpm}$ for $10 \mathrm{~min}$. 
TT, APTT, PT, and FIB were tested with commercial kits following the manufacturer's instructions by a coagulometer (Model LG-PABER-I, Steellex Co., Beijing, China). All the compounds were dissolved in PBS with 20\% DMSO, and the concentration was $100 \mu \mathrm{M}$. TT was determined by incubating $40 \mu \mathrm{L}$ PPP solution for $3 \mathrm{~min}$ at $37^{\circ} \mathrm{C}$, followed by addition of $40 \mu \mathrm{L}$ thrombin solution and $20 \mu \mathrm{L}$ sample for $3 \mathrm{~min}$ at $37^{\circ} \mathrm{C}$. APTT was determined by incubating $10 \mu \mathrm{L}$ sample solution and $50 \mu \mathrm{L}$ PPP solution with $50 \mu \mathrm{L}$ APTT-activating agent for $3 \mathrm{~min}$ at $37^{\circ} \mathrm{C}$, followed by the addition of $50 \mu \mathrm{L} \mathrm{CaCl}$. PT was determined by incubating $40 \mu \mathrm{L}$ PPP solution for $3 \mathrm{~min}$ at $37^{\circ} \mathrm{C}$, followed by the addition of $40 \mu \mathrm{L}$ thromboplastin agent and $20 \mu \mathrm{L}$ sample. FIB was determined by incubating $10 \mu \mathrm{L}$ PPP solution with $90 \mu \mathrm{L}$ imidazole buffer for $3 \mathrm{~min}$ at $37^{\circ} \mathrm{C}$, followed by addition of $50 \mu \mathrm{L}$ FIB agent and $10 \mu \mathrm{L}$ sample solution. By measuring the prolongation of the plasma clotting time of thrombin time (TT), activated partial thromboplastin time (APTT), INR increase in prothrombin time (PT), and reduction in fibrinogen (FIB) content, the antithrombotic activity was assessed.

\section{Conclusions}

Scutellarin (1) is effective in treating cardiovascular diseases and cerebrovascular injury [12]; nevertheless, clinical application is limited because of its poor solubility and low bioavailability. In this study, we introduced a sulfonic group at the C-8 position of scutellarein (2), which increased the aqueous solubility obviously. Further, DPPH-radical scavenging ability assay and antithrombic assay also proved that the sulfonated derivative (3) still retained the bioactivity of parent compounds. This kind of scutellarein derivative (3) could be an efficient agent for ischemic cerebrovascular disease treatment.

Supplementary Materials: The following are available online: IR and ${ }^{1} \mathrm{H}-\mathrm{NMR}$ spectrums of 2 and 3.

Acknowledgments: This work was supported by National Natural Science Foundation of China (No. 81274058, 21302225), China Scholarship Council (No. 201407060046), Natural Science Foundation of Jiangsu Province (BK20151563), 333 High-level Talents Training Project Funded by Jiangsu Province, Six Talents Project Funded by Jiangsu Province (2013-YY-010), Program for Excellent Talents in School of Pharmacy of Nanjing University of Chinese Medicine (15ZYXET-1), Jiangsu Collaborative Innovation Center of Chinese Medicinal Resources Industrialization (ZDXMHT-1-13), Project Funded by the Priority Academic Program Development of Jiangsu Higher Education Institutions and Project Funded by the Flagship Major Development of Jiangsu Higher Education Institutions (PPZY2015A070), Key Laboratory of Therapeutic Material of Chinese Medicine, Jiangsu Province, State Key Laboratory Cultivation Base for TCM Quality and Efficacy, Nanjing University of Chinese Medicine.

Author Contributions: T.G., Y.Z., Y.-T.L., Y.S., Z.-X.D., W.-Y.W., X.X., F.F. and H.-M.L. did the experiments, N.-G.L. designed the synthetic route, Z.-H.S. wrote this paper and Y.-P.T. revised this paper.

Conflicts of Interest: All authors declare no financial/commercial conflict of interests.

\section{References}

1. Donnan, G.A.; Fisher, M.; Macleod, M.; Davis, S.M. Stroke. Lancet 2008, 371, 1612-1623. [CrossRef]

2. Murray, C.J.; Lopez, A.D. Mortality by cause for eight regions of the world. Global Burden of Disease Study. Lancet 1997, 349, 1269-1276. [CrossRef]

3. Sturm, J.W.D.; Helen, M.; Donnan Geoffrey, A.; Macdonell Richard, A.L.; McNeil John, J.; Thrift Amanda, G. Handicap after stroke: How does it relate to disability, perception of recovery, and stroke subtype?: The North East Melbourne Stroke Incidence Study (NEMESIS). Stroke 2002, 33, 762-768. [CrossRef] [PubMed]

4. Clarke, P.; Mashall, V.; Black, S.E.; Colantonio, A. Well-being after stroke in Canadian seniors: Findings from the Canadian Study of Health and Aging. Stroke 2002, 33, 1016-1021. [CrossRef] [PubMed]

5. Liu, H.; Yang, X.; Ren, T.; Feng, Y.; Xu, H. Effects of Erigeron breviscapus ethanol extract on neuronal oxidative injury induced by superoxide radical. Fitoterapia 2005, 76, 666-670. [CrossRef] [PubMed]

6. Tao, Y.H.; Jiang, D.Y.; Xu, H.B.; Yang, X.L. Inhibitory effect of Erigeron breviscapus extract and its flavonoid components on GABA shunt enzymes. Phytomedicine 2008, 15, 92-97. [CrossRef] [PubMed]

7. Zhang, W.D.; Chen, W.S.; Wang, Y.H.; Yang, G.J.; Kong, D.Y.; Li, H.T. Studies on the flavone glycosides from the extract of Erigeron breviscapus. Chin. Tradit. Herb. Drugs 2000, 31, 565-568. 
8. Hu, Q.; Dai, L.L.; Wang, L.; Xiao, Y.H.; Pan, Z.Q. Study on optimization of extraction and separation processes of breviscapine. Chem. Bioeng. 2009, 26, 58-60.

9. Ke, Y.; Bao, T.; Wu, X.; Tang, H.; Wang, Y.; Ge, J.; Fu, B.; Meng, X.; Chen, L.; Zhang, C.; et al. Scutellarin suppresses migration and invasion of human hepatocellular carcinoma by inhibiting the STAT3/Girdin/Akt activity. Biochem. Biophys. Res. Commun. 2016, 483, 509-515. [CrossRef] [PubMed]

10. Li, Q.; Chen, Y.; Zhang, X.; Zuo, S.; Ge, H.; Chen, H.; Chen, Y.; Liu, X.; Zhang, J.H.; Ruan, H.; et al. Scutellarin attenuates vasospasm through the Erk5-KLF2-eNOS pathway after subarachnoid hemorrhage in rats. J. Clin. Neurosci. 2016, 34, 264-270. [CrossRef] [PubMed]

11. Zhao, S.; Sun, Y.; Li, X.; Wang, J.; Yan, L.; Zhang, Z.; Wang, D.; Dai, J.; He, J.; Wang, S. Scutellarin inhibits RANKL-mediated osteoclastogenesis and titanium particle-induced osteolysis via suppression of NF- $\mathrm{KB}$ and MAPK signaling pathway. Int. Immunopharmacol. 2016, 40, 458-465. [CrossRef] [PubMed]

12. Wei, Y.; Li, L.; Xi, Y.; Qian, S.; Gao, Y.; Zhang, J. Sustained release and enhanced bioavailability of injectable scutellarin-loaded bovine serum albumin nanoparticles. Int. J. Pharm. 2014, 476, 142-148. [CrossRef] [PubMed]

13. Cao, F.; Guo, J.X.; Ping, Q.N.; Liao, Z.G. Prodrugs of scutellarin: Ethyl, benzyl and N,N-diethylglycolamide ester synthesis, physicochemical properties, intestinal metabolism and oral bioavailability in the rats. Eur. J. Pharm. Sci. 2006, 29, 385-393. [CrossRef] [PubMed]

14. Hu, X.M.; Zhou, M.M.; Hu, X.M.; Zeng, F.D. Neuroprotective effects of scutellarin on rat neuronal damage induced by cerebral ischemia/reperfusion. Acta Pharmacol. Sin. 2005, 26, 1454-1459. [CrossRef] [PubMed]

15. Jiang, R.J.; Yang, B.; Liu, Z.K.; Zhao, Y.L.; Liao, H.L.; Yang, J.; Gao, C.Z.; Wang, F.; Han, B. A novel polyrotaxane-based delivery system for scutellarin: Preparation, characterization, and in vitro evaluation. Carbohydr. Res. 2013, 380, 149-155. [CrossRef] [PubMed]

16. Xiao, L.; Yi, T.; Chen, M.; Lam, C.W.; Zhou, H. A new mechanism for increasing the oral bioavailability of scutellarin with Cremophor EL: Activation of MRP3 with concurrent inhibition of MRP2 and BCRP. Eur. J. Pharm. Sci. 2016, 93, 456-467. [CrossRef] [PubMed]

17. Li, N.G.; Shen, M.Z.; Wang, Z.J.; Tang, Y.P.; Shi, Z.H.; Fu, Y.F.; Shi, Q.P.; Tang, H.; Duan, J.A. Design, synthesis and biological evaluation of glucose-containing scutellarein derivatives as neuroprotective agents based on metabolic mechanism of scutellarin in vivo. Bioorg. Med. Chem. Lett. 2013, 23, 102. [CrossRef] [PubMed]

18. Zhang, J.L.; Che, Q.M.; Li, S.Z.; Zhou, T.H. Study on metabolism of scutellarin in rats by HPLC-MS and HPLC-NMR. J. Asian Nat. Prod. Res. 2003, 5, 249-256. [CrossRef] [PubMed]

19. Qian, L.H.; Shen, M.Z.; Tang, H.; Tang, Y.P.; Zhang, L.; Fu, Y.F.; Shi, Q.P.; Li, N.G. Synthesis and protective effect of scutellarein on focal cerebral ischemia/reperfusion in rats. Molecules 2012, 17, 10667-10674. [CrossRef] [PubMed]

20. Tang, H.; Tang, Y.P.; Li, N.G.; Shi, Q.P.; Guo, J.M.; Shang, E.X.; Duan, J.A. Neuroprotective effects of scuetellarin and scutellarin repeatedly cerebral ischemia-reperfusion in rats. Pharmacol. Biochem. Behav. 2014, 118, 51-59. [CrossRef] [PubMed]

21. Woźnicka, E.; Pieniążek, E.; Zapała, L.; Byczyński, Ł.; Trojnar, I.; Kopacz, M. New sulfonic derivatives of quercetin as complexing reagents: Synthesis, spectral, and thermal characterization. J. Therm. Anal. Calorim. 2015, 120, 351-361. [CrossRef]

22. Cui, Y.; Han, Y.; Yang, X.; Sun, Y.; Zhao, Y. Protective effects of quercetin and quercetin- $5^{\prime}, 8$-disulfonate against carbon tetrachloride-caused oxidative liver injury in mice. Molecules 2013, 19, 291-305. [CrossRef] [PubMed]

23. Boyer, J.; Brown, D.; Liu, R.H. Uptake of quercetin and quercetin 3-glucoside from whole onion and apple peel extracts by Caco-2 Cell monolayers. J. Agric. Food Chem. 2004, 52, 7172-7179. [CrossRef] [PubMed]

24. Kang, T.B.; Liang, M.C. Studies on the inhibitory effects of quercetin on the growth of HL460 leukemia cells. Biochem. Pharmacol. 1997, 54, 1013-1018. [CrossRef]

25. Suh, D.K.; Lee, E.J.; Kim, H.C.; Kim, J.H. Induction of G1/S phase arrest and apoptosis by quercetin in human osteosarcoma cells. Arch. Pharm. Res 2010, 33, 781-785. [CrossRef] [PubMed]

26. Zhang, H.; Zhang, M.; Yu, L.; Zhao, Y.; He, N.; Yang, X. Antitumor activities of quercetin and quercetin-5',8-disulfonate in human colon and breast cancer cell lines. Food Chem. Toxicol. Int. J. Publ. Br. Ind. Biol. Res. Assoc. 2012, 50, 1589-1599. [CrossRef] [PubMed]

27. Hess, S.; Akermann, M.A.; Wnendt, S.; Zwingenberger, K.; Eger, K. Synthesis and immunological activity of water-soluble Thalidomide prodrugs. Bioorg. Med. Chem. 2001, 9, 1279. [CrossRef] 
28. Kim, M.K.; Park, K.S.; Yeo, W.S.; Choo, H.; Chong, Y. In vitro solubility, stability and permeability of novel quercetin-amino acid conjugates. Bioorg. Med. Chem. 2009, 17, 1164-1171. [CrossRef] [PubMed]

29. Cheng, X.L.; Rasqué, P.; Vatter, S.; Merz, K.H.; Eisenbrand, G. Synthesis and cytotoxicity of novel indirubin-5-carboxamides. Bioorg. Med. Chem. 2010, 18, 4509-4515. [CrossRef] [PubMed]

30. Li, N.G.; Song, S.L.; Shen, M.Z.; Tang, Y.P.; Shi, Z.H.; Tang, H.; Shi, Q.P.; Fu, Y.F.; Duan, J.A. Mannich bases of scutellarein as thrombin-inhibitors: Design, synthesis, biological activity and solubility. Bioorg. Med. Chem. 2012, 20, 6919-6923. [CrossRef] [PubMed]

31. Shi, Z.H.; Li, N.G.; Shi, Q.P.; Zhang, W.; Dong, Z.X.; Tang, Y.P.; Zhang, P.X.; Gu, T.; Wu, W.Y.; Fang, F.; et al. Synthesis of scutellarein derivatives to increase biological activity and water solubility. Bioorg. Med. Chem. 2015, 23, 6875-6884. [CrossRef] [PubMed]

Sample Availability: Samples of the compounds 1, 2 and 3 are available from the authors.

(C) 2017 by the authors. Licensee MDPI, Basel, Switzerland. This article is an open access article distributed under the terms and conditions of the Creative Commons Attribution (CC BY) license (http:/ / creativecommons.org/licenses/by/4.0/). 